\title{
PERBEDAAN EFEK ANALGESIK AMITRIPTILIN, GABAPENTIN, DAN PREGABALIN PADA NEUROPATI DIABETIK DAN NEURALGIA TRIGEMINAL
}

\author{
COMPARATIVE ANALGESIC EFFECTS OF AMITRIPTYLINE, GABAPENTIN, \\ AND PREGABALIN IN DIABETIC NEUROPATHY AND TRIGEMINAL NEURALGIA
}

Ibnu Putra, * Yuneldi Anwar, * Khairul Putra Surbakti*

\begin{abstract}
Introduction: The management of neuropathic pain is a challenge for clinicians because of its nonspecific and difficult clinical to treat characteristics. The use of antidepressant drugs such as amitriptyline and anticonvulsants such as gabapentin and pregabalin has shown various efficacy overcoming neuropathic pain.

Aim: To compare the analgesic efficacy of amitriptyline, gabapentin, and pregabalin in patients with diabetic neuropathy and trigeminal neuralgia.

Methods: This is an experimental pre and post test study on patients with diabetic neuropathy and trigeminal neuralgia in neurology clinic Haji Adam Malik Hospital, Medan, from April 2015 to March 2017. In each disease, subjects were divided into three groups, each was treated either with oral amitriptyline 12.5mg, gabapentin 100mg, or pregabalin $75 \mathrm{mg}$ twice daily. The Numeric Rating Scale to assess pain intensity were examined before and after two weeks after treatment.
\end{abstract}

Results: The number of diabetic neuropathy subjects was 75, while trigeminal neuralgia subjects was 30, each were divided into three groups treated either with amitriptyline, gabapentin, or pregabalin. There were no differences on pain intensity changes in diabetic neuropathy groups but significant differences were shown in trigeminal neuralgia groups.

Discussion: Amitriptyline, gabapentin, and pregabalin effective to lower pain intensity in trigeminal neuralgia significantly compare to diabetic neuropathy.

Keywords: Amitriptyline, diabetic neuropathy, gabaptentin, pregabalin, trigeminal neuralgia

\section{ABSTRAK}

Pendahuluan: Pengelolaan nyeri neuropatik merupakan tantangan bagi klinisi karena karakteristik klinisnya yang nonspesifik dan tatalaksananya yang sulit. Penggunaan antidepresan seperti amitriptilin dan antikonvulsan seperti gabapentin dan pregabalin mempunyai efikasi yang berbeda-beda dalam mengatasi nyeri neuropatik.

Tujuan: Mengetahui perbedaan efek analgesik dari amitriptilin, gabapentin, dan pregabalin pada penderita neuropati diabetik dan neuralgia trigeminal.

Metode: Studi eksperimental pre dan post test terhadap pasien neuropati diabetik atau neuralgia trigeminal yang berobat ke Poliklinik Neurologi RSUP Haji Adam Malik, Medan, sejak bulan April 2015 hingga Maret 2017. Semua subjek dibagi menjadi tiga kelompok untuk setiap penyakit, yang masing-masing mendapatkan amitriptilin 12,5mg, gabapentin $100 \mathrm{mg}$, dan pregabalin $75 \mathrm{mg}$, dengan frekuensi pemberian obat dua kali sehari setiap kelompok. Pengukuran intensitas nyeri dengan menggunakan Numeric Rating Scale dilakukan sebelum dan setelah dua minggu pengobatan.

Hasil: Didapatkan subjek dengan neuropati diabetik sebanyak 75 orang dan neuralgia trigeminal 30 orang yang masing-masing dibagi menjadi 3 kelompok dengan terapi amitriptilin, gabapentin, dan pregabalin. Tidak terdapat perbedaan rerata perubahan intensitas nyeri yang bermakna pada kelompok neuropati diabetik, namun bermakna pada subjek neuralgia trigeminal.

Diskusi: Amitriptilin, gabapentin, dan pregabalin memiliki efikasi dalam menurunkan intensitas nyeri pada neuralgia trigeminal secara bermakna dibandingkan pada neuropati diabetik.

Kata kunci: Amitriptilin, gabapentin, neuralgia trigeminal, neuropati diabetik, pregabalin

*Departemen Neurologi FK Universitas Sumatera Utara/RSUP Haji Adam Malik, Medan. Korespondensi: ibnuputrapulungan@gmail.com. 


\section{PENDAHULUAN}

Nyeri merupakan mekanisme pertahanan tubuh yang membantu memberikan tanda bahwa sedang terjadi kerusakan jaringan atau akan terjadi kerusakan jaringan. ${ }^{1}$ Nyeri dapat diklasifikasikan menjadi tiga jenis, yaitu nyeri nosiseptif, nyeri neuropatik, dan nyeri campuran. ${ }^{2}$ Berdasarkan International Association for the Study of Pain (IASP) nyeri neuropatik didefinisikan sebagai nyeri yang diikuti oleh sebuah lesi primer atau disfungsi dari sistem saraf somatosensorik. ${ }^{3}$ Pengelolaan nyeri neuropatik merupakan tantangan bagi klinisi karena karakteristik klinisnya yang nonspesifik dan tatalaksananya yang sulit. ${ }^{4}$

Neuropatidiabetik merupakan bentukneuropati yang paling umum di negara-negara industri. ${ }^{5}$ Biasanya pasien mengalami gangguan terutama pada anggota gerak bawah dan bermanifestasi berupa kehilangan sensasi, nyeri terbakar, parastesia, atau kelemahan otot, hingga memengaruhi aktivitas sehari-hari. ${ }^{6}$ Selain neuropati diabetik, nyeri neuropatik lainnya yang bersifat fokal mengenai saraf trigeminal adalah neuralgia trigeminal. ${ }^{2}$ Gejala neuralgia trigeminal berupa serangan nyeri pada wajah unilateral dan bersifat spontan, episodik, menusuk, seperti tersengat listrik, yang melibatkan cabang kesatu (N. Oftalmika), kedua (N. Maksilaris), dan ketiga (N. Mandibularis), dan dicetuskan oleh stimulus tertentu. ${ }^{7-9}$

Amitriptilin merupakan salah satu pengobatan lini pertama untuk nyeri neuropatik. ${ }^{10}$ Akhir-akhir ini penggunaan obat antikonvulsan seperti gabapentin dan pregabalin dalam mengatasi nyeri neuropatik telah berkembang pesat. ${ }^{11-12}$

Beberapa penelitian telah menunjukkan efikasi masing-masing obat dalam mengatasi nyeri neuropati diabetik. ${ }^{13-14}$ Gabapentin dianggap lebih superior dibandingkan amitriptilin dalam menurunkan intensitas nyeri pada penderita nyeri neuropati diabetik, ${ }^{15}$ sementara tidak ada perbandingan yang signifikan antara amitriptilin dengan pregabalin dalam menurunkan intensitas nyeri. ${ }^{16}$ Pemberian gabapentin dan pregabalin pada penderita neuralgia trigeminal menunjukkan efikasi yang baik dalam menurunkan intensitas nyeri. ${ }^{17-18}$

\section{TUJUAN}

Mengetahui perbedaan efek analgesik antara amitriptilin, gabapentin, dan pregabalin terhadap perubahan intensitas nyeri pada penderita neuropati diabetik dan neuralgia trigeminal.

\section{METODE}

Penelitian eksperimental dengan rancangan pre-post test terhadap pasien neuropati diabetik atau neuralgia trigeminal yang berobat ke Poliklinik Neurologi RSUP Haji Adam Malik, Medan, sejak bulan April 2015 hingga Maret 2017. Kriteria eksklusi adalah semua pasien dengan riwayat alergi terhadap amitriptilin/gabapentin/pregabalin, mempunyai penyakit/gangguan hati dan ginjal, riwayat stroke, gangguan psikiatri, serta sedang hamil atau menyusui.

Pada penelitian ini diagnosis neuropati diabetik ditegakkan berdasarkan anamnesis, pemeriksaan fisik, dan neurologis menggunakan sistem skoring. Salah satu sistem penilaian baru yang dikembangkan adalah Diabetic Neuropathy Symptom (DNS) Score dan Diabetic Neuropathy Examination (DNE) Score. Sistem penilaian DNS terdiri dari empat kriteria yang telah divalidasi dengan nilai prediktif yang tinggi untuk mendeteksi neuropati diabetik pada penderita diabetes. Gejala-gejala seperti ketidakseimbangan dalam berjalan serta nyeri neuropatik seperti rasa terbakar, parastesi, dan rasa kebas merupakan komponen yang dinilai. Jika terdapat gejala tersebut diberi nilai satu dengan nilai maksimum empat. Nilai 1 atau lebih diinterpretasikan sebagai positif neuropati diabetik.

Adapun sistem penilaian DNE terdiri dari dua pemeriksaan kekuatan otot, satu pemeriksaan refleks, dan lima pemeriksaan sensorik. Masing-masing pemeriksaan di beri nilai 0-2 (nilai 0 normal dan 2 sangat terganggu). Nilai maksimum adalah 16 dan dikatakan positif neuropati diabetik jika skor DNE $\geq 3 .{ }^{19-20}$ Diagnosis neuralgia trigeminal berdasarkan kriteria diagnosis Konsensus Nasional Diagnostik dan Penatalaksanaan Nyeri Kepala IV. ${ }^{8}$ Pengukuran intensitas nyeri menggunakan Numeric Rating Scale (NRS) yang dilakukan pada awal dan akhir terapi.

Subjek dibagi menjadi tiga kelompok untuk masing-masing penyakit dan diberikan amitriptilin 
Tabel 1. Karakteristik Subjek dengan Neuropati Diabetik $(n=75)$

\begin{tabular}{|c|c|c|c|c|}
\hline \multirow[b]{2}{*}{ Variabel } & \multirow[b]{2}{*}{ Total } & \multicolumn{3}{|c|}{ Kelompok } \\
\hline & & $\begin{array}{l}\text { Amitriptilin } \\
\qquad(n=25)\end{array}$ & $\begin{array}{c}\text { Gabapentin } \\
\qquad(n=25)\end{array}$ & $\begin{array}{c}\text { Pregabalin } \\
(n=25)\end{array}$ \\
\hline \multicolumn{5}{|l|}{ Jenis kelamin (\%) } \\
\hline - Laki-laki & $44(58,7)$ & $16(21,3)$ & $16(21,3)$ & $12(16,0)$ \\
\hline - Perempuan & $31(41,3)$ & $9(12,0)$ & $9(12,0)$ & $13(17,3)$ \\
\hline Umur (tahun) & $58,34 \pm 6,94$ & $59,36 \pm 6,10$ & $57,68 \pm 6,62$ & $54,80 \pm 7,56$ \\
\hline Durasi DM (tahun) & $6,56 \pm 3,18$ & $6,44 \pm 2,51$ & $6,48 \pm 3,38$ & $6,76 \pm 3,67$ \\
\hline $\operatorname{IMT}\left(\mathrm{kg} / \mathrm{m}^{2}\right)$ & $23,87 \pm 3,34$ & $24,21 \pm 3,82$ & $23,80 \pm 2,14$ & $23,79 \pm 3,80$ \\
\hline HbA1c (\%) & $7,79 \pm 1,02$ & $7,78 \pm 1,01$ & $7,93 \pm 1,24$ & $7,66 \pm 0,78$ \\
\hline \multicolumn{5}{|l|}{ Rerata NRS } \\
\hline - Preterapi & $5,76 \pm 0,99$ & $5,88 \pm 1,05$ & $5,64 \pm 1,03$ & $5,76 \pm 0,92$ \\
\hline - Pascaterapi & $3,24 \pm 0,83$ & $3,56 \pm 0,96$ & $3,08 \pm 0,81$ & $3,12 \pm 0,88$ \\
\hline
\end{tabular}

DM: diabetes melitus; IMT: indeks massa tubuh; NRS: numeric rating scale.

Tabel 2. Karakteristik Subjek dengan Neuralgia Trigeminal $(n=30)$

\begin{tabular}{lcccc}
\hline \multicolumn{1}{c}{ Variabel } & Total & \multicolumn{3}{c}{ Kelompok } \\
\cline { 3 - 5 } & & $\begin{array}{c}\text { Amitriptilin } \\
(\mathbf{n = 1 0})\end{array}$ & $\begin{array}{c}\text { Gabapentin } \\
(\mathbf{n = 1 0})\end{array}$ & $\begin{array}{c}\text { Pregabalin } \\
(\mathbf{n = 1 0})\end{array}$ \\
\hline $\begin{array}{l}\text { Jenis kelamin (\%) } \\
\text { - Laki-laki }\end{array}$ & $10(33,3)$ & $6(20,0)$ & $1(3,3)$ & $3(10,0)$ \\
- Perempuan & $20(66,7)$ & $4(13,3)$ & $9(30,0)$ & $7(23,3)$ \\
Umur (tahun) & $56,03 \pm 12,32$ & $53,6 \pm 10,81$ & $56 \pm 12,99$ & $58,5 \pm 13,77$ \\
Rerata NRS & & & & $6,5 \pm 0,53$ \\
- Preterapi & $5,97 \pm 0,76$ & $5,3 \pm 0,48$ & $6,1 \pm 0,74$ & $4 \pm 0,67$ \\
- Pascaterapi & $3,87 \pm 0,63$ & $3,9 \pm 0,57$ & $3,7 \pm 0,67$ & \\
\hline
\end{tabular}

NRS: numeric rating scale.

12,5mg untuk kelompok I, gabapentin 100mg untuk kelompok II, dan pregabalin 75mg untuk kelompok III. Tiap obat diberikan secara oral, dua kali sehari selama dua minggu.

Analisis deskriptif digunakan untuk melihat gambaran karakteristik subjek penelitian. Untuk mengetahui perbedaan efek amitriptillin, gabapentin dan pregabalin terhadap perubahan intensitas nyeri berdasarkan NRS sebelum dan setelah terapi digunakan uji one way ANOVA jika data berdistribusi normal atau uji Kruskal-Wallis jika data tidak berdistribusi normal.

\section{HASIL}

Terdapat 75 subjek dengan nyeri neuropati diabetik dan 30 subjek dengan neuralgia trigeminal yang masing-masing dibagi lagi menjadi 3 kelompok dengan terapi amitriptilin, gabapentin, dan pregabalin. Pada subjek dengan neuropati diabetik, tiap kelompok terdiri dari 25 subjek yang mayoritas adalah laki-laki $(58,7 \%)$ dan rerata usia 58,3 $\pm 6,94$ tahun (Tabel 1).

Rerata durasi atau lamanya menderita diabetes melitus adalah 6,56 $( \pm 3,18)$ tahun, dengan durasi paling rendah adalah 3 tahun dan paling tinggi adalah 14 tahun. Rerata NRS seluruh subjek neuropati diabetik sebelum diberikan obat adalah 5,76 $( \pm 0,99)$, sedangkan rerata NRS seluruh subjek neuropati diabetik setelah diberikan obat adalah $3,24( \pm 0,83)$

Pada kelompok neuralgia trigeminal, tiap kelompok terdiri dari 10 subjek yang mayoritas perempuan $(66,7 \%)$ dan rerata usia $56,03 \pm 12,32$ tahun (Tabel 2).

Tabel 3 menunjukkan tidak terdapat perbedaan yang bermakna antara rerata perubahan nilai NRS pre dan pascaterapi ketiga jenis obat pada subjek neuropati diabetik $(\mathrm{p}=0,354)$, namun terdapat 
Tabel 3. Perbedaan Rerata Nilai NRS Pre dan Pascaterapi pada Neuropati Diabetik (n=75) dan Neuralgia Trigeminal $(\mathbf{n}=\mathbf{3 0})$

\begin{tabular}{lcccc}
\hline \multicolumn{1}{c}{ Kelompok } & $\begin{array}{c}\Delta \text { NRS } \\
\text { Neuropati Diabetik }\end{array}$ & $\mathbf{p}^{*}$ & $\begin{array}{c}\Delta \text { NRS } \\
\text { Neuralgia Trigeminal }\end{array}$ & $\mathbf{p}^{*}$ \\
\hline Amitriptilin & $2,32 \pm 0,85$ & & $1,40 \pm 0,52$ & \\
Gabapentin & $2,56 \pm 0,87$ & 0,354 & $2,40 \pm 0,69$ & $<0,001$ \\
Pregabalin & $2,64 \pm 0,70$ & & $2,50 \pm 0,53$ & \\
\hline
\end{tabular}

*Uji one way ANOVA; $\triangle \mathrm{NRS}$ : perubahan nilai numeric rating scale pre dan pascaterapi.

Tabel 4. Efek samping Amitriptillin, Gabapentin, dan Pregabalin pada Kedua Kelompok

\begin{tabular}{lrrrr}
\hline \multirow{2}{*}{ Jenis Obat } & \multicolumn{2}{c}{ Kelompok Neuropati Diabetik } & \multicolumn{2}{c}{ Kelompok Neuralgia Trigeminal } \\
$(\mathbf{n = 7 5 )}$ & \multicolumn{1}{c}{ Dizziness } & Mengantuk & \multicolumn{1}{c}{ Dizziness } \\
\cline { 2 - 5 } & Mengantuk & - & $4(40 \%)$ & - \\
\hline Amitriptilin & $6(24 \%)$ & $5(20 \%)$ & $1(10 \%)$ & $4(40 \%)$ \\
Gabapentin & $3(12 \%)$ & $4(16 \%)$ & $1(10 \%)$ & $3(30 \%)$ \\
Pregabalin & $2(8 \%)$ & &
\end{tabular}

perbedaan yang bermakna pada kelompok dengan neuralgia trigeminal $(\mathrm{p}<0,001)$.

Pada penelitian ini didapatkan efek samping berupa dizziness terutama pada kelompok yang mendapat gabapentin, yaitu $20 \%$ pada kelompok neuropati diabetik dan 40\% pada kelompok neuralgia trigeminal. Pada kelompok yang mendapat amitriptillin, terdapat efek samping berupa rasa mengantuk baik pada kelompok neuropati diabetik (24\%) maupun neuralgia trigeminal (40\%).

\section{PEMBAHASAN}

Pada penelitian ini didapatkan mayoritas subjek dengan nyeri neuropati diabetik adalah lakilaki $(58,7 \%)$, sesuai dengan Tanenberg dkk yang menyatakan bahwa laki-laki lebih banyak mengalami neuropati diabetik dibandingkan perempuan. Umumnya laki-laki memiliki panjang badan yang lebih tinggi dibandingkan perempuan, sehingga penderita diabetes laki-laki lebih rentan mengalami neuropati diabetik dibandingkan perempuan. ${ }^{21}$

Berdasarkan penelitian ini terdapat perbedaan yang tidak bermakna dari perubahan intensitas nyeri sebelum dan sesudah pemberian ketiga jenis obat pada subjek neuropati diabetik. Hal ini sesuai dengan Boyle dkk dan Bansal dkk yang menyatakan terdapat perubahan intensitas nyeri setelah pemberian amitriptilin dan pregabalin, tetapi tidak ada perbedaan efek yang bermakna dari kedua jenis tersebut. ${ }^{16,22}$
Adapun Devi $\mathrm{dkk}^{23}$ menyatakan penurunan intensitas nyeri yang bermakna baik pada kelompok gabapentin, pregabalin, ataupun duloksetin, tetapi tidak terdapat perbedaan yang bermakna antara ketiga kelompok tersebut.

Penelitian ini tidak seperti penelitian sebelumnya, yaitu observasi dan titrasi dosis obat yang singkat, sehingga tidak dapat melihat efek samping jangka panjang. Pada subjek dengan neuropati diabetik juga tidak dipertimbangkan terkontrol tidaknya kadar glukosa. Hal ini didukung oleh penelitian lainnya bahwa terdapat perbaikan konduksi saraf pascaterapi insulin yang intensif dibandingkan dengan terapi konvensional. ${ }^{24}$ Kadar glukosa yang terkontrol merupakan hal yang penting dalam mengatasi neuropati diabetik, walaupun bukan satu-satunya terapi. ${ }^{25}$

Mayoritas subjek neuralgia trigeminal penelitian ini adalah perempuan (66,7\%). Hal ini sesuai dengan Denny dkk, Bennetto dkk, dan Obermann yang menyatakan insiden neuralgia trigeminal hampir dua kali lebih banyak pada perempuan dibandingkan dengan laki-laki. ${ }^{7,26-27}$ Rerata usia subjek ini adalah $56,03 \pm 12,32$, sesuai dengan Denny dkk yang menyatakan trigeminal klasik terjadi pada usia 50 tahun ke atas. ${ }^{7}$

Terdapat perbedaan yang bermakna dari perubahan intensitas nyeri neuralgia terigeminal sebelum dan sesudah pemberian ketiga jenis obat 
$(p<0,001)$. Akhir-akhir ini, lebih banyak penelitian yang mengombinasikan antara pregabalin dengan amitriptilin, pregabalin dengan karbamazepin, dan kombinasi ketiganya (pregabalin, amitriptilin, dan karbamazepin) sebagai terapi neuralgia trigeminal. ${ }^{28}$ Tetapi hal ini tidak dapat dijadikan sebagai acuan utama dalam memberikan terapi pada penderita neuralgia trigeminal, karena tidak di bandingkan dengan pemberian terapi lini pertama.

Terapi lini pertama untuk nyeri neuropatik adalah antidepresan trisiklik dan serotoninnorepinephrin reuptake inhibitor (SSRI), calcium channel $\alpha_{2}-\delta$ ligands (gabapentin dan pregabalin), dan lidokain topikal. ${ }^{25,29-32}$ Sejak tahun 1970, antidepresan trisiklik seperti trimipramin dan amitriptilin merupakan pengobatan lini pertama untuk neuropati diabetik, yaitu dapat menghilangkan rasa nyeri dari stimulus suhu, mekanik, dan elektrik pada penderita diabetik. ${ }^{33}$

Gabapentin dan pregabalin bekerja melalui beberapa mekanisme yang dapat memiliki efek yang dapat mengurangi rasa nyeri pada penderita nyeri neuropatik. Kedua jenis obat ini merupakan analog sintetis dari gamma-aminobutyric acid (GABA) yang berikatan atau bekerja secara selektif pada subunit $\alpha_{2} \delta$ dari kanal kalsium. ${ }^{34}$ Sebagai efeknya adalah inhibisi dari pelepasan neurotransmiter eksitatorik, seperti glutamat dan noradrenalin, serta memodulasi pelepasan substansi P. ${ }^{6,35}$ Mekanisme lainnya adalah kedua jenis obat ini bersifat antagonis dengan reseptor $N$-methyl-D-aspartate (NMDA) dan alphaamino-3-hydroxy-5-methyl-4-isoxazolepropionic acid (AMPA). ${ }^{34,36}$

Pada penelitian ini didapatkan perbedaan yang tidak bermakna dari ketiga jenis obat pada penderita neuropati diabetik. Hal ini bisa disebabkan antara lain dosis yang tidak dititrasi dan waktu observasi yang singkat. Berbeda dengan subjek neuralgia diabetik, terdapat perbedaan yang bermakna dari ketiga jenis obat sebagai analgesik. Hal ini sesuai dengan penelitian sebelumnya bahwa penggunaan gabapentin dan pregabalin merupakan pilihan terapi lini kedua. Adapun amitriptillin hanya memiliki manfaat yang minimal dalam mengatasi neuralgia trigeminal. ${ }^{37}$
Pada penelitian ini didapatkan efek samping dizziness pada kelompok neuropati diabetik yang menggunakan gabapentin $(20 \%)$ dan pregabalin $(16 \%)$, serta kelompok neuralgia trigeminal yang menggunakan gabapentin $(40 \%)$ dan pregabalin $(30 \%)$. Terdapat pula efek sedatif pada penggunaan gabapentin dan pregabalin, sesuai dengan penelitian sebelumnya bahwa efek samping yang lebih sering muncul pada gabapentin dan pregabalin adalah dizziness dan efek sedatif. ${ }^{34}$ Pada penggunaan amitriptillin, efek samping berupa rasa mengantuk pada kelompokneuropati diabetik(24\%) danneuralgia trigeminal (40\%) yang masih dapat ditoleransi oleh subjek. Hal ini sesuai dengan penelitian lain adanya efek sedatif merupakan efek samping tersering akibat amitriptillin dibandingkan pregabalin pada penderita neuropati diabetik. ${ }^{16}$

Penelitian ini memiliki beberapa keterbatasan. Pertama, desain penelitian ini adalah kuasi eksperimen tanpa randomisasi pada unit-unit samplingnya. Dengan desain ini, tidak dapat ditetapkan hubungan kausal yang pasti antara perlakuan dengan hasil yang diukur, terutama jika terdapat variabel perancu yang tidak dapat sepenuhnya dikendalikan. Kedua, pemberian obat tidak diawasi secara langsung, sehingga tidak dapat disingkirkan kemungkinan ketidakteraturan minum obat pada pasien. Ketiga jumlah sampel dan waktu observasi yang singkat sehingga tidak dapat menilai efek samping penggunaan jangka panjang.

\section{KESIMPULAN}

Amitriptilin, gabapentin, dan pregabalin memiliki efikasi dalam menurunkan intensitas nyeri pada neuralgia trigeminal secara bermakna dibandingkan pada neuropati diabetik.

\section{DAFTAR PUSTAKA}

1. Cohen SP, Mao J. Neuropathic pain: mechanisms and their clinical implications. BMJ. 2014;348:1-12.

2. Baron R, Binder A, Wasner G. Neuropathic pain: diagnosis, pathophysiological mechanisms, and treatment. Lancet Neurol. 2010;9(8):807-19.

3. Gilron I. Treatment of neuropathic pain: antiepileptic and antidepressant drugs. Dalam: Raja SN, Sommer CL, editor. Pain 2014: refresher course, 15th world congress on pain. Washington: IASP Press; 2014.

4. Mishra S, Bhatnagar S, Goyal GN, Rana SP, Upadhya SP. A comparative efficacy of amitriptyline, 
gabapentine, and pregabaline in neuropathic cancer pain: a prospective randomized double-blind placebo-controlled study. Am J Hospice \& Palliative Med. 2012;29(3):177-82.

5. Said G. Diabetic neuropathy. Advanced Studies in Medicine. 2001;1(11):457-9.

6. Sadeli HA. Nyeri neuropati diabetik. Dalam: Meliala KL, Suraymiharja A, Wirawan R, Sadeli HA, dan Amir D, editor. Nyeri neuropatik. Yogyakarta: Medigama Press; 2008. h. 138-47.

7. Denny C, Priya J, Ongole R. Neuralgia trigeminal: current consept in the medical management. World $\mathrm{J}$ Dent. 2010;1(1):43-6.

8. Sjahrir H, Machfoed MH, Suharjanti I, Basir $\mathrm{H}$, Adnyan MO, editor. Konsensus nasional IV diagnostik dan penatalaksanaan nyeri kepala. Surabaya: Airlangga University Press; 2013.

9. Suryamiharja A, Purwata TE, Suharjanti I, Yudiyanta. Konsensus nasional 1 diagnostik dan penatalaksanaan nyeri neuropatik. Surabaya: Airlangga University Press. 2011. h. 19-21.

10. O'connor AB, Dworkin RH. Treatment of neuropathic pain: an overview of recent guidelines. Am J Med. 2009;122(10):s22-s32.

11. Gilron I, Flatters SJ. Gabapentin and pregabalin for the treatment of neuropathic pain: A review of laboratory and clinical evidence. Pain Res Manage. 2006;11(Supl A):16A-29A.

12. Maizels M, Mccarberg B. Antidepressants and antiepileptic drugs for chronic non-cancer pain. Am Fam Physician. 2005;71(3):483-90.

13. Frampton JE, Scott LJ. Pregabalin in the treatment of painful diabetic peripheral neuropathy. Drugs. 2004;64(24):2813-20.

14. Serpell MG, Bibby SJ, Maton S, Babatola FD, Batchelor G, Bone M, dkk. Gabapentin in neuropathic pain syndromes: a randomised, double-blind, placebocontrolled trial. Pain. 2002;99(3):557-66.

15. Dallachio C, Buffa C, Mazzarello P, Chiroli S. Gabapentin versus amitriptyline in painful diabetic neuropathy: an open-label pilot study. J Pain Symptom Manage. 2000;20(4):280-5.

16. Bansal D, Bhansali A, Hota D, Chakrabarti A, Dutta P. Amitriptyline vs pregabalin in painful diabetic neuropathy: a randomized double blind clinical trial. Diabet Med. 2006;26(10):1019-26.

17. Obermann M, Yoon MS, Sensen K, Maschke M, Diener HC, Katsarava Z. Efficacy of pregabalin in the treatment of neuralgia trigeminal. Cephalalgia. 2007;28(2):174-81.

18. Qazi JA, Qureshi W, Qazi AH. Gabapentin for the treatment of neuralgia trigeminal. Pakistan Oral and Dental J. 2012;32(2):218-21.
19. Meijer JG, Bosma E, Lefrandt JD, Links TP, Smit AJ, Stewart RE, dkk. Clinical diagnosis of diabetic polyneuropathy with the diabetic neuropathy symptom and diabetic neuropathy examination scores. Diabetes Care. 2003;26(3):697-701.

20. Meijer JG, Smit AJ, Sonderen EV, Groothoff JW, Eisma WH, Links TP. Symptom scoring systems to diagnose distal polyneuropathy in diabetes: the diabetic neuropathy symptom score. Diabet Med. 2002;19(11):962-5.

21. Tanenberg RJ. Diabetic peripheral neuropathy: painful or painless. Hospital Physician. 2009;45(7):1-8.

22. Boyle J, Eriksson ME, Gribble L, Gouni R, Johnsen S, Coppini DV, dkk. Randomized, plasebo-controlled comparison of amitriptyline, duloxetine, and pregabalin in patients with chronic diabetic peripheral neuropathic pain. Diabetes Care. 2012;35(12):24518.

23. Devi P, Madhu K, Ganapathy B, Sarma GRK, John L, Kulkarni C. Evaluation of efficacy and safety of gabapentin, duloxetine, and pregabalin in patients with painful diabetic peripheral neuropathy. Indian J Pharmacol. 2012;44(1):51-6.

24. Yagihashi S, Mizukami H, Sugimoto K. Mechanism of diabetic neuropathy: where are we now and where to go. J Diabetes Investig. 2011;2(1):18-32.

25. Callaghan BC, Cheng HT, Stables CL, Smith AL, Feldman EL. Diabetic neuropathy: clinical manifestations and current treatments. Lancet Neurol. 2012;11(6):521-34.

26. Bennetto L, Patel NK, Fuller G. Trigeminal neuralgia and its management. BMJ. 2007;334(7586):201-5.

27. Obermann M. Treatment options in trigeminal neuralgia. Ther Adv Neurol Disord. 2010;3(2):10715.

28. Taheri A, Firouzi-Marani S, Khoshbin M, Beygi M. A retrospective review of efficacy of combination therapy with pregabalin and carbamazepine versus pregabalin and amitriptyline in treatment of trigeminal neuralgia. Anaesth Pain Intensive Care. 2015;19(1):8-12.

29. O'connor AB, Dworkin RH. Treatment of neuropathic pain: an overview of recent guidelines. The American J Med. 2009; 122(10):s22-32.

30. Argoff CE, Backonja M-M, Belgrade MJ, Bennett GJ, Clark MR, Cole BE, dkk. Consensus guidelines: treatment planning and options. Mayo Clin Proc. 2006;81(4):S12-25.

31. Lindsay TJ, Rodgers BC, Savath V, Hettinger K. Treating diabetic peripheral neuropathic pain. Am Fam Physician. 2010;82(2):151-8.

32. Zakrzewska JM. Medical management of trigeminal neuropathic pains. Expert Opin Pharmacother. 2010;11(8):1239-54. 
33. Spruce MC, Potter J, Coppini D. The pathogenesis and management of painful diabetic neuropathy: a review. Diabetic Medicine. 2003;20(2):88-98.

34. Gilron I, Flatters SJL. Gabapentin and pregabalin for the treatment of neuropathic pain: a review of laboratory and clinical evidence. Pain Res Manage. 2006;11(Suppl A):16A-29A.

35. Banday M, Sameer AS, Farhat S, Aziz R. Gabapentin: a pharmacotherapeutic panacea. Int J Pharm Pharm Si. 2013;5(3):84-94.
36. Varkonyi T, Kempler P. Diabetic neuropathy: new strategies for treatment. Diabetes, Obesity, and Metabolism. 2008;10(2):99-108.

37. Al-Quliti KW. Update on neuropathic pain treatment for trigeminal neuralgia. The pharmacological and surgical options. Neurosci. 2015;20(2):107-14. 